\title{
Participação da Família no Tratamento em Saúde Mental como Prática no Cotidiano do Serviço
}

\author{
Pedro Pablo Sampaio Martins \\ Carla Guanaes-Lorenzi \\ Universidade de São Paulo
}

\begin{abstract}
RESUMO - Transformações na lógica do cuidado em saúde mental, no Brasil, deram início a um importante debate sobre o lugar da família no tratamento. No contexto desse debate, o presente artigo tem por objetivo compreender como familiares de pacientes de um Hospital-Dia constroem sentidos sobre sua participação no tratamento. Foram conduzidas 10 entrevistas. A análise temática realizada apontou para cinco formas de participação dos entrevistados no tratamento. São elas: cuidado à família, aprendizado sobre a doença mental, transformação das relações familiares, cuidado com o familiar em semi-internação e cuidado mútuo entre as famílias. Discutimos como a construção do apoio às famílias ocorre no cotidiano do serviço por meio do investimento na qualidade das relações entre profissionais, pacientes e familiares.
\end{abstract}

Palavras-chave: família, saúde mental, terapêutica

\section{Family Participation in Mental Health Treatment as Daily Practice in a Day Hospital}

\begin{abstract}
Changes in Brazilian mental healthcare gave rise to an important debate about the place of family in treatment. In the context of this debate, this article aims to understand how family members of patients, who were seen in a Day-Hospital, make meaning about their participation in treatment. Ten interviews were conducted. Thematic analysis pointed to five different forms of family participation in treatment. These forms are: family support, learning about the mental illness, transformation of family relationships, offering support to the family member who is being treated, and mutual care between different families. The way family support is constructed in daily practices (particularly through the investment in the quality of relationships between professionals, patients, and family members) is discussed.
\end{abstract}

Keywords: family, mental health, therapeutics

O presente estudo tem como interesse a participação da família no tratamento em saúde mental. Essa temática tem ganhado destaque na literatura científica brasileira, especialmente a partir do investimento em um modelo de cuidado em saúde que se preocupa em oferecer apoio aos indivíduos em sofrimento mental e a seus familiares, em uma lógica de cidadania e de compromisso social (Cavalheri, 2010; Silva \& Monteiro, 2011). Nesse cenário, observamos a convivência de discursos advindos de diferentes modelos de assistência, asilar e psicossocial (Costa-Rosa, 2000). Associados a diferentes entendimentos sobre família, adoecimento mental e tratamento, esses modelos implicam em formas de cuidado à família bastante distintas.

A figura do manicômio ou hospital psiquiátrico é talvez a imagem mais lembrada quando se trata da temática da saúde mental. Por anos, o cuidado nesse campo teve como principal e, muitas vezes, única estratégia a internação integral dos pacientes gravemente acometidos por transtornos mentais. Esse modelo de assistência é conhecido como asilar porque era comum a internação dos pacientes para toda a vida, o que implicava em uma indesejada cronicidade das doenças e altos custos para a saúde pública (Costa-Rosa, 2000).

No Brasil, as primeiras políticas preocupadas com a doença mental datam apenas da segunda metade do século

1 Endereço para correspondência: Avenida dos Bandeirantes, 3900. Bairro Monte Alegre, Ribeirão Preto, SP, Brasil. CEP: 14.040-901.

E-mail: pedropablomartins@gmail.com
XIX. Elas foram marcadas por processos de marginalização e exclusão social. Com um entendimento escasso acerca do fenômeno da loucura e da doença mental, a incipiente psiquiatria da época consistia em uma atividade mais política do que terapêutica. Os manicômios caracterizavam-se como espaços de segregação e exclusão, pouco voltados ao cuidado (Guanaes, 2000). Com este tipo de prática, a família não tinha lugar de destaque no debate em saúde mental, e era considerada como mais uma parte da sociedade a ser protegida da influência negativa do convívio com a loucura (Silva \& Monteiro, 2011). De forma geral, portanto, observou-se nesse modo de atenção a atribuição do cuidado do sofrimento mental às instituições psiquiátricas, afastando os doentes de suas famílias.

Entretanto, esse cenário seria transformado de forma significativa a partir da articulação de críticas advindas de dentro da própria psiquiatria. O movimento da Reforma Psiquiátrica Brasileira, compreendido "como um conjunto de transformações de práticas, saberes, valores culturais e sociais" (Brasil, 2005) surgiu nesse contexto. Ele se caracterizou por críticas à hegemonia do saber biomédico no cuidado à saúde mental, bem como às infelizes consequências testemunhadas durante anos pela segregação e exclusão social, promovidas a partir do modelo asilar (Costa-Rosa, 2000).

Entende-se a Reforma como um processo que se faz também no cotidiano institucional e no âmbito das relações 
interpessoais, nos quais se promovem avanços e retrocessos, impasses, conflitos, tensões e desafios (Brasil, 2005). A fim de contemplar essas mudanças, a transição para um modo psicossocial de atenção à saúde tem sido a estratégia adotada. Testemunhamos, assim, transformações e revisões nas relações entre serviço, usuários e suas famílias.

Em função tanto das mudanças na concepção de saúde, quanto das transformações dos serviços oferecidos, o discurso acerca da necessidade e importância da participação da família no cuidado de seus parentes diagnosticados com transtornos mentais ganhou destaque. Oficialmente, a família passou a ser posicionada como parceira do tratamento nos novos ambientes de atendimento (Brasil, 2005), sendo construída como unidade de atenção e cuidado.

Assim, segundo Serapioni (2005), existe consenso atualmente acerca da importância de: “1) retomar a família como unidade de atenção das políticas públicas; 2) desenvolver redes de apoio e de envolvimento das famílias e comunidade; 3) realizar uma melhor integração entre famílias, serviços públicos e iniciativa do setor informal" (p. 249). Observa-se, portanto, uma valorização da família como parte do tratamento. Contudo, os entendimentos sobre as formas como isso deve acontecer são diversos e, muitas vezes, contrastantes. Essa família é apresentada ora como parceira do tratamento, ora como sistema a ser cuidado.

Estudos como os de Felício e Almeida (2008), Goodman e Happell (2006) e Gross e Goldin (2008) argumentam sobre a abordagem à família em tratamentos terapêuticos como sendo decisiva e vital à resposta de pacientes psiquiátricos. Nesses casos, a família é incluída como parte integrante do tratamento do paciente. Há também estudos que descrevem programas de intervenção nos quais a família se torna uma unidade específica de cuidado e ganha intervenções pensadas particularmente para ela (Kondo \& Wada, 2009; Lucksted, Stewart \& Forbes, 2008; Toumbourou \& Bamberg, 2008), dentre as quais se destacam as estratégias de psicoeducação (Aman, 2005; Rose \& Shelton, 2006).

Esses estudos demonstram uma crescente compreensão sobre a importância da família no tratamento de uma doença mental. Entretanto, esse não é um processo que ocorre sem tensões e contradições. Alguns pesquisadores (Cavalheri, 2010; Gonçalves \& Sena, 2001; Pinho, Hernández \& Kantorski, 2010) denunciam a simples devolução da enfermidade para a família, mediante a desarticulação dos manicômios, sem que tenha havido a criação efetiva de recursos de assistência substitutivos. Segundo eles, essas mudanças não consideraram adequadamente a estrutura social para a qual se devolviam os doentes.

Assim, novas demandas acabaram sendo impostas às famílias, que se encontram sobrecarregadas e desamparadas. Tornam-se, muitas vezes, um "bode expiatório" no qual se passou a localizar a responsabilidade pelo cuidado ao doente mental. Vasconcelos (1990) alerta para os riscos desse processo. Segundo o autor, a desinstitucionalização, se ingenuamente tomada por desospitalização, promove uma "reprivatização compulsória da loucura na família ou simplesmente um processo de negligência social em caso de sua ausência" (p. 233).

Como consequência, a literatura aponta uma disputa pela responsabilização entre famílias e instituições pelo cuidado do doente. Pinho et al. (2010), por exemplo, alertam sobre práticas que têm como resquício uma atenção normalizadora e concentrada no poder disciplinar, as quais estabelecem relações de tutela e culpabilização das famílias. Gonçalves e Sena (2001) chamam atenção para a mesma tensão. Por um lado, profissionais de saúde às vezes exigem que a família aceite a doença sem que a ela seja oferecido suporte. Por outro, as famílias, herdeiras do discurso médico da hospitalização, exercem pressão para que as instituições psiquiátricas mantenham a custódia de seus parentes.

Nesse contexto, o modo de participação da família no cuidado em saúde mental aparece como questão a ser pensada pelos profissionais e pesquisadores da área (Rosa, 2005). Como nós, profissionais da saúde e pesquisadores, posicionamos essa família ao entender a importância de convidá-la a participar do tratamento? Queremos reforçar discursos de culpabilização pelo adoecimento e de patologização da família? Ou desejamos nos engajar em práticas que de fato legitimem a dificuldade e fragilidade da situação em que essas pessoas se encontram?

Ainda que historicamente recente, esta importância da parceria tem sido tão enfaticamente destacada pelos pesquisadores da área que seria de se esperar, já agora, encontrar nos serviços formas de organização e funcionamento que de fato a privilegiassem. Contudo, essa mesma literatura denuncia as dificuldades encontradas nas instituições, tanto considerando a falta de recursos e estrutura que tornem a participação da família possível, quanto, e mais importante, a mudança da lógica oferecida nesse cuidado (Rosa, 2005; Silva \& Monteiro, 2011).

A pesquisa relatada neste artigo insere-se nesse cenário, e foi realizada no contexto de um programa de assistência familiar de um Hospital-Dia de Psiquiatria (HD) (Martins, 2013). Hospitais-Dia fazem parte da rede extrahospitalar de assistência em Saúde Mental, oferecendo uma alternativa de tratamento voluntário intensivo e centrado na reabilitação psicossocial. Situam-se em um nível de assistência intermediário entre a internação e o atendimento ambulatorial. Influenciado pelos princípios da Comunidade Terapêutica (De Leon, 2003), o tratamento nesse tipo de instituição valoriza os vínculos e o convívio dos pacientes com familiares, profissionais e comunidade como forma de cuidado.

Coerente com essa lógica, o HD onde o presente estudo ocorreu possui um programa de assistência familiar que tem como objetivo oferecer orientação e suporte emocional à família, considerando sua relação com a doença mental. Esse programa conta com o envolvimento de uma equipe multidisciplinar.

Este estudo foi delineado com interesse na relevância que o cuidado com as famílias tem tomado no campo da saúde mental, em geral, e no HD, em específico. Ele se insere em um contexto teórico e prático atual de contradições. Ao mesmo tempo em que se entende a importância da atenção às famílias nos serviços, não há consensos nem sobre as razões desta importância, nem sobre as maneiras de responder a ela (Rosa, 2005).

Consideramos os familiares como atores centrais na construção do cuidado psicossocial em saúde mental. Acreditamos, portanto, que escutá-los e valorizar o seu 
próprio saber - seus entendimentos sobre o que lhes é benéfico - pode ser um caminho para o aperfeiçoamento do trabalho com as famílias nesse campo.

Assim, o objetivo deste artigo é compreender como familiares de pacientes de um Hospital-Dia constroem sentidos sobre a participação da família no tratamento em saúde mental. Especificamente, este estudo visa: (a) compreender quais processos vividos no serviço são reconhecidos como ações de cuidado à família; e (b) refletir sobre o modo como, a partir desses entendimentos, o cuidado à família se concretiza como possibilidade no cotidiano do serviço.

\section{Método}

\section{Delineamento Teórico-Metodológico}

Esta pesquisa foi desenvolvida em uma perspectiva qualitativa de cunho construcionista social, cuja premissa básica define que o conhecimento é criado e sustentado por meio de práticas compartilhadas. A investigação construcionista está primordialmente interessada em compreender os processos pelos quais as pessoas descrevem e explicam o mundo no qual vivem (Gergen, 1997). Para Spink (2004), esse tipo de concepção valoriza a compreensão dos significados produzidos pelas pessoas a respeito de si mesmas, dos outros e do mundo, a partir de relacionamentos circunscritos por um contexto sócio-histórico e cultural, e suas implicações para a construção de práticas sociais. A pesquisa é vista como um processo coproduzido por pesquisador e pesquisado que, imersos em múltiplos relacionamentos, trazem para ela seus diálogos, construindo e reconstruindo as descrições da vida social (McNamee \& Hosking, 2011). A pesquisa construcionista social está comprometida em dar visibilidade ao processo de produção de sentidos e à multiplicidade de versões possíveis sobre um mesmo tema, considerando suas implicações para os contextos nos quais se produzem.

\section{Contexto}

O presente estudo aconteceu em um HD, ligado a um Hospital Universitário. Essa instituição é parte da rede de saúde mental de uma cidade de médio porte no interior do estado de São Paulo. Especificamente, um programa de assistência à família foi o contexto mais imediato do estudo. Esse programa oferece diferentes atividades que visam a dar suporte aos familiares de pacientes atendidos na instituição.

Existem no HD quatro modalidades de atendimento especificamente pensadas para a participação das famílias no tratamento (Guanaes-Lorenzi et al., 2012). Os grupos familiares ocorrem com a participação de pacientes, expacientes e familiares e têm o objetivo de promover um espaço de diálogo entre equipe, pacientes e familiares acerca de temas que lhes interessem. Os grupos de cuidadores funcionam como espaço de apoio, acolhimento e orientação para familiares de pacientes atuais e daqueles em pós-alta.
As reuniões familiares ocorrem semanalmente com cada família em específico - paciente e familiares - e são um contexto que visa ao diálogo sobre questões trazidas por aquela família acerca de sua vida cotidiana, adoecimento mental e a dinâmica familiar. Por fim, as visitas domiciliares têm o objetivo de aproximação ao contexto cotidiano dos pacientes e familiares, além da construção de vínculos com eles e sua comunidade.

\section{Participantes}

Participaram deste estudo 10 familiares de pacientes atendidos em regime de semi-internação no HD. Eles tinham idades estimadas entre 28 e 70 anos. Com relação ao parentesco desses familiares com os pacientes do HD, foram entrevistados cinco mães (1. Anna; 2. Sandra; 6. Rose; 8. Amanda; 9. Lúcia), três pais (5. Mário; 7. Paulo; 10. Fernando), uma filha (4. Luísa) e uma esposa (3. Lia).

Foram convidadas a participar do estudo todas as 21 famílias com as quais conseguimos contato e que foram atendidas no HD desde o início da atuação da assistente social responsável pelo programa à época. Os critérios de inclusão utilizados referem-se aos familiares, que deveriam (a) ter sido acompanhantes do paciente em seu período de semiinternação no HD; (b) ter participado em diversas atividades oferecidas no programa de atendimento às famílias; e (c) expressar seu desejo de participar por meio de leitura conjunta com o pesquisador, e posterior assinatura, do Termo de Consentimento Livre e Esclarecido.

\section{Procedimentos de Construção e Análise do Corpus de Pesquisa}

Foram conduzidas, na instituição, entrevistas individuais semiestruturadas com os 10 participantes voluntários, com duração média de uma hora, que tiveram como eixos de investigação suas compreensões sobre família, doença mental e participação no tratamento. As entrevistas foram gravadas em áudio (mp3) e transcritas na íntegra. Todos os nomes citados foram trocados por outros diferentes. A fim de preservar o modo da fala e seus sentidos, a linguagem coloquial foi mantida nas transcrições. Os parâmetros éticos foram observados durante toda sua execução, considerando a Resolução 196/96 para pesquisas envolvendo seres humanos (Brasil, 1996), vigente à época de realização do estudo. O projeto foi submetido, avaliado, aprovado e acompanhado pelos Comitês de Ética em Pesquisa responsáveis, tanto da instituição de ensino na qual a pesquisa estava submetida, quanto da instituição de saúde onde o estudo ocorreu.

Para dar visibilidade aos temas conversados, conduzimos uma análise temática das entrevistas inspirada em Spink (2010). Essa autora entende que os temas construídos se tornam possíveis a partir de processos de produção de sentidos, nos quais pesquisadores e participantes se engajam na pesquisa. Considerando categorias como práticas discursivas (Spink, 2004), observamos que a própria estrutura da entrevista favoreceu a produção de narrativas que organizavam a experiência relatada pelos familiares em 
uma dimensão temporal associada à sua passagem pelo HD: aspectos de sua vida antes, durante e depois de seu período na instituição. Observando o objetivo deste artigo, selecionamos para análise a categoria "Famílias no tratamento", que agrupa os temas emergentes na interação de pesquisa relacionadas ao período de vida dos familiares durante sua passagem pelo HD. Para dar destaque ao modo como esses temas eram vividos no cotidiano, eles foram divididos em subtemas. A partir disso, selecionamos trechos das entrevistas que descreviam ações concretas referentes à sua presença no cotidiano dos familiares entrevistados, a fim de ilustrá-los.

\section{Resultados e Discussão}

O que, para os familiares entrevistados, foi sua participação no tratamento? Como eles significam esse processo? Que elementos foram importantes? Como se produz cuidado? Selecionando nas entrevistas as informações sobre os diferentes modos como essa participação acontecia e os processos vividos como de ajuda no contexto deste programa de atendimento, construímos cinco temas que as agrupam de maneira a dar visibilidade à experiência narrada por estes familiares acerca de sua participação no tratamento no HD, discutidos na Tabela 1 .

\section{Cuidado à Família}

Os familiares descrevem sua participação como sendo uma forma de se sentirem acolhidos, cuidados e apoiados mediante as situações colocadas com o adoecimento de seu familiar. O HD é descrito, assim, como um espaço para reflexão, autocuidado e fortalecimento pessoal no enfrentamento dos desafios da doença mental. Na prática, os familiares descrevem a sensação de serem cuidados no HD como acontecendo de diversas maneiras. Bastante citado, o acolhimento é a primeira delas, chamando atenção para os efeitos benéficos de determinados modos de interação na rotina do serviço.

Paulo: E a mesma coisa que eu acho que eu vou tirar o chapéu é pro... Pro atendimento, vamos dizer, humano. Cada pessoa que você chega aqui, a qualquer hora, mesmo nas primeiras vezes, todo mundo cumprimenta. Mas cumprimenta olhando no seu olho. Depois familiariza... E mesmo antes disso, uh? Nunca falta um sorriso. "Bom dia." Sorriso. Parece uma coisa boba, mas pra quem tá chegando nessa situação é uma... um tom, um acolhimento, uma coisa... bem diferenciada. (Entrevista 7, Paulo, pai)

Além disso, as famílias são cuidadas em contextos que favorecem tanto a reflexão sobre a própria vida - questões do cotidiano, comportamentos, relacionamentos, etc. - quanto o fortalecimento pessoal: "Então, assim, eu acho fundamental isso porque as pessoas se analisam também. Se refletem. Refletem seus valores, entendeu?" (Entrevista 1, Anna, mãe).

A família também se sente cuidada ao se ver acompanhada por profissionais qualificados, que têm o conhecimento necessário para sua atuação. Isso gera um sentimento de segurança nos familiares, que finalmente se sentem amparados: "Então, a gente sente como que se protegido assim. 'Não, eu tenho alguém que me vê, né, que vê, que me ajuda, que pode me direcionar, né?' É muito bom, menino. Muito bom" (Entrevista 2, Sandra, mãe).

Tabela 1 Experiências das Famílias no Tratamento

\begin{tabular}{|c|c|c|}
\hline Tema & Vivência do tema no cotidiano & $\begin{array}{l}\text { Familiares que relatam este tipo de } \\
\text { acontecimento no serviço }\end{array}$ \\
\hline \multirow[t]{3}{*}{ Cuidado à Família. } & Acolhimento. & $\begin{array}{l}\text { 1. Anna; 3. Lia; 5. Mário; 6. Rose; 7. Paulo; } 8 . \\
\text { Amanda; 9. Lúcia; 10. Fernando. }\end{array}$ \\
\hline & $\begin{array}{l}\text { Espaço para reflexão sobre si e fortalecimento } \\
\text { pessoal. }\end{array}$ & $\begin{array}{l}\text { 1. Anna; 2. Sandra; 3. Lia; 4. Luísa; 5. Mário; } 7 . \\
\text { Paulo; 8. Amanda; 9. Lúcia. }\end{array}$ \\
\hline & $\begin{array}{l}\text { Sentimento de segurança: trabalho feito por } \\
\text { profissionais qualificados. }\end{array}$ & 2. Sandra; 5. Mário; 7. Paulo; 8. Amanda. \\
\hline \multirow[t]{3}{*}{$\begin{array}{l}\text { Aprendizado Sobre a } \\
\text { Doença Mental. }\end{array}$} & $\begin{array}{l}\text { Diagnóstico e/ou aceitação da existência da } \\
\text { doença. }\end{array}$ & 2. Sandra; 5. Mário; 6. Rose. \\
\hline & Informações sobre a doença. & 2. Sandra; 6. Rose; 8. Amanda; 10. Fernando. \\
\hline & $\begin{array}{l}\text { Informações sobre como lidar com situações } \\
\text { advindas da doença. }\end{array}$ & 2. Sandra; 4. Luísa; 5. Mário; 6. Rose. \\
\hline $\begin{array}{l}\text { Transformação de Relações } \\
\text { Familiares. }\end{array}$ & Espaço de diálogo sobre questões familiares. & $\begin{array}{l}\text { 2. Sandra; 3. Lia; 5. Mário; 8. Amanda; 9. Lúcia; } \\
\text { 10. Fernando. }\end{array}$ \\
\hline \multirow[t]{2}{*}{$\begin{array}{l}\text { Cuidado com o Familiar em } \\
\text { Semi-Internação. }\end{array}$} & $\begin{array}{l}\text { Sentimento de segurança e cuidado para o } \\
\text { paciente. }\end{array}$ & 1. Anna; 3. Lia; 4. Luísa; 6. Rose; 7. Paulo. \\
\hline & Participação como responsabilidade. & 2. Sandra; 4. Luísa. \\
\hline \multirow[t]{3}{*}{$\begin{array}{l}\text { Cuidado Mútuo Entre as } \\
\text { Famílias. }\end{array}$} & $\begin{array}{l}\text { Sentimento de não ser o único a passar pela } \\
\text { experiência da doença mental. }\end{array}$ & $\begin{array}{l}\text { 1. Anna; 2. Sandra; 5. Mário; 6. Rose; 7. Paulo; } 9 \\
\text { Lúcia. }\end{array}$ \\
\hline & Própria experiência ajuda aos outros. & 1. Anna; 3. Lia; 5. Mário; 6. Rose; 7. Paulo. \\
\hline & Ampliação da Rede Social & 1. Anna; 2. Sandra; 3. Lia; 4. Luísa; 7. Paulo. \\
\hline
\end{tabular}


Esses temas nos permitem refletir sobre como o cuidado à família se produz em um contexto como o do programa de atendimento estudado. Pensando nas descrições de acolhimento, da construção de um espaço para reflexão pessoal e do sentimento de segurança por ser acompanhado por profissionais qualificados, observamos como esse cuidado se constrói como possibilidade não apenas mediante o convite para participação, mas por meio do investimento cotidiano na qualidade das relações entre os atores envolvidos no processo.

Assim, torna-se possível entender a construção desse cuidado como parte de um momento interativo. Essa compreensão chama atenção para o potencial de cada encontro dentro do serviço e de suas consequências para as relações entre familiares e profissionais, quando fatos cotidianos transformam significativamente a experiência de participar de um tratamento. O caso de Paulo, que cita ser recebido com um sorriso toda vez que chega ao serviço, exemplifica esse tipo de transformação. Nesse caso, o acolhimento citado pelos entrevistados pode ser também relacionado ao acolhimento como diretriz da Política Nacional de Humanização que, segundo o Ministério da Saúde (Brasil, 2010), inaugura e sustenta processos de cuidar. Como orientação ética, esse acolhimento implica a escuta do usuário e a interação a partir das necessidades e questões por ele trazidos, produzindo uma lógica de corresponsabilidade. A partir dessa compreensão, o acolhimento não é algo que se faz em um dado momento do serviço, mas que deve acontecer em todos os contextos e todas as interações a ele relacionadas. Muitos relatos das entrevistas por nós analisadas chamam a atenção exatamente para esse aspecto.

\section{Aprendizado sobre a Doença Mental}

A participação no tratamento é descrita como uma forma de aprendizado sobre o que é a doença mental e maneiras de lidar com ela. Segundo os entrevistados, por meio do contato com a equipe profissional e com os outros familiares, o HD tornou-se um espaço de referência para obter informações e recursos técnicos relacionados ao quê e a como fazer ao enfrentar determinadas situações com seu familiar adoecido. $\mathrm{O}$ aprendizado sobre a doença e seus efeitos benéficos para as famílias acontecem no cotidiano do tratamento dessas famílias, por meio do diagnóstico e aceitação da doença, do recebimento de informações sobre a doença e como lidar com situações advindas da mesma.

Rose: Ah, foi bom, porque... Muito das coisas que eu não entendia da doença mental... Porque pra mim, na minha mente, eu pensava que a mente não adoecia. (...) Mas ai os psiquiatras, eles me explicaram que isso era dos transtornos fisicos, hormônios, é... Pode fazer a pessoa ter pensamentos alterados, né? Então isso foi muito bom pra mim entender. Porque na época eu fiquei completamente perdida. (Entrevista 6, Rose, mãe)

Mário: Mas, a partir do momento que o sujeito aceita que realmente o paciente é doente, que o parente é doente... E ele começa a frequentar aqui. Ele vai ter que vim com fé também no pessoal, com confiança de... Dele participar, dele aprender.
Porque, veja bem, olha: quando o filho sai daqui, você sabe como tratar ele lá fora. (Entrevista 5, Mário, pai)

A descrição dessa forma de participação da família no tratamento reforça a utilização de estratégias de psicoeducação como benéficas para os familiares (Aman, 2005; Rose \& Shelton, 2006). Conforme já citado, a criação de programas que visam a levar didaticamente informações às famílias tem sido uma preocupação dos profissionais da área. Segundo descrevem algumas narrativas produzidas nesta pesquisa, o acesso à informação especializada - possibilitado mediante a participação da família no tratamento - ajuda os familiares na produção de estratégias cotidianas de cuidado para com o familiar. Além disso, esse conhecimento muitas vezes transforma a natureza da relação entre paciente e familiares, com o entendimento de que determinados comportamentos estão associados a sintomas de uma patologia que, muitas vezes, não estão sob o controle da própria pessoa.

Entretanto, algumas questões parecem pertinentes sobre esse modo de participação. Em primeiro lugar, é preciso refletir com relação ao diagnóstico e seu impacto na vida do usuário e na vida familiar. A esse respeito, Gergen (1997) problematiza o lugar central no qual o diagnóstico tem sido posicionado no cuidado em saúde. Busca, assim, refletir sobre suas consequências negativas para a cultura em geral, tais como um assustador crescimento da patologização de diferentes comportamentos, a manutenção da hierarquia social e estigmatização individual. Utilizados sem reflexão sobre seus efeitos, os diagnósticos podem chegar à família - leiga tanto no vocabulário psiquiátrico técnico-científico quanto no entendimento do processo de produção de conhecimento subjacente a esse mesmo vocabulário - como uma verdade estável definidora de suas relações.

Por outro lado, como a própria descrição de Rose sugere, muitas vezes o diagnóstico é vivido pela família como um alívio e, a partir disso, mudanças no relacionamento com o paciente se tornam possíveis. Sendo assim, o diagnóstico pode também ser encarado como uma forma encontrada por essas pessoas - usuários e familiares - de finalmente dar sentido a experiências que antes lhes pareciam confusas.

Somemos a isso a complexidade de entender o diagnóstico como prática cotidiana no serviço e instrumento de ação política. Vivemos em um mundo no qual o diagnóstico, como prática institucionalizada, funciona como base para a tomada de diversas decisões importantes, desde a escolha de medicamentos e procedimentos clínicos, até a possibilidade de acesso a recursos de previdência social. Nesse sentido, Campos (2001) critica como a idealização da loucura e negação da doença acabam negando também dificuldades concretas e materiais do viver com o sofrimento psíquico.

Portanto, é preciso sempre problematizar o lugar do diagnóstico em contexto, para que não seja nem descartado como inteiramente destrutivo, nem entendido de maneira irrefletida como a solução única para os problemas da saúde mental. Assim, a reflexão sobre o diagnóstico em cada caso específico torna-se fundamental, pois é apenas levando em consideração seu uso cotidiano e as ações que possibilita ou restringe que podemos ter pistas se este paralisa ou alivia (Guanaes-Lorenzi, Palacio, Aoki, \& Tofoli, 2015). Nesse caso, uma estratégia reflexiva para abordar essa questão no cotidiano da prática pode consistir em refletir com a família 
sobre a possibilidade do diagnóstico mudar ao longo do tempo.

Para finalizar este tema, vale a pena discutir sobre o que se toma por aprendizado e como e onde ele se torna possível. Ao mesmo tempo em que pensar estratégias específicas de psicoeducação para a família pode ser um recurso importante, é preciso lembrar que o aprendizado no serviço vai além de uma prática formal e institucionalizada. Como os entrevistados mencionaram, o aprendizado acontece em diferentes contextos e por meio de seu contato com outros atores envolvidos no cotidiano da instituição, incluindo pacientes e familiares. Mais uma vez, aparece como relevante o contato entre os diferentes atores presentes no cotidiano do serviço, constituindo-o como um possível local de investimento para a produção do cuidado à família no tratamento.

\section{Transformação de Relações Familiares}

A participação da família no tratamento é compreendida como uma oportunidade para cuidar das relações entre os membros da família. Esse processo é muitas vezes descrito como doloroso e difícil, mas como tendo um resultado positivo para as interações familiares no decorrer do tratamento. Na descrição dos entrevistados, esse modo de participação no tratamento acontece predominantemente nas reuniões familiares, em que sessões de atendimento são oferecidas a cada família separadamente.

Lia: Porque mexeu comigo, né? A nossa relação foi discutida. Pesquisador: Unhum. Entendi. Você acha que discutir a relação de vocês, então, é... Mudou alguma coisa pro João.

Lia: Mudou. [pausa] E mudou pra mim também. Porque eu vi que eu posso cobrar. Atenção, carinho, é... (Entrevista 3, Lia, esposa)

Mário: E aqui um dia ele falou assim: “Ó, pai, agora abriu uma janela pra gente poder se comunicar e tal. Eu tinha dificuldade de lidar com o senhor..." Será que era por causa da doença? Não sei, né... (...) E ai ele começou a mudar, o Adriano, quando aconteceu isso. Porque não tinha papo, não tinha conversa lá em casa, cê entendeu?! Não existia conversa lá. Ai ele começou a conversar, chegava em casa batia papo, comentava as coisas daqui, cê entendeu, que ele não comentava nada. (Entrevista 5, Mário, pai)

É importante notar que a transformação das relações familiares tipicamente vinha associada, nas falas dos participantes, ao contexto de uma atividade específica do programa de atendimento à família, qual seja, as chamadas reuniões familiares. Essas reuniões caracterizam-se por sessões de atendimento familiar das quais participam profissionais e membros de uma mesma família. Desse modo, tal atividade aproxima-se de uma perspectiva clínica dentro de uma instituição pública de saúde, o que abre espaço para algumas reflexões.

De acordo com Campos (2001), visões reducionistas do discurso sanitário promovido a partir da reforma do sistema de saúde brasileiro produziram uma infeliz separação da clínica com relação aos serviços substitutivos, como se ela necessariamente se opusesse à prevenção e produção da saúde. Defendendo que qualquer planejamento em saúde eficaz deve contar com uma interlocução clínica, esta autora advoga pela atribuição da responsabilidade à clínica ampliada de observar e cuidar tanto das necessidades epidemiológicas e sociais quanto das demandas dos indivíduos. Entende, assim, que os problemas de saúde, ainda que localizados em grupos e comunidades, se "encarnam em doentes concretos" (p. 99). Esta reflexão é especialmente profícua quando associada ao presente tema, considerando que a autora sugere como diretriz para o resgate da clínica nesses contextos o trabalho com famílias. Para ela, esse tipo de prática pode ser um aliado na manutenção e fortalecimento dos laços sociais dos usuários, imprescindível para o sucesso de qualquer tratamento em saúde mental.

Assim, pensando o contexto das reuniões familiares, essa prática foi descrita pelos entrevistados como uma forma de participação que beneficiou a todos os familiares, promovendo não somente seu fortalecimento pessoal, mas também a possibilidade de discussão de seus relacionamentos e um consequente fortalecimento de seus vínculos. Para isso, é importante ressaltar, os profissionais do HD têm se dedicado à aprendizagem de alguns recursos teóricos e técnicos advindos, originalmente, da terapia familiar que consideram as contribuições construcionistas sociais para o campo (McNamee \& Gergen, 1992), aproximando-as reflexivamente para seu contexto de trabalho.

A lógica deste trabalho problematiza os discursos dominantes sobre doença mental e convida a narrativas que entendem a doença como parte, e não determinação, da vida. Contudo, uma ressalva deve ser feita: a clínica à qual Campos (2001) se refere não deve estar restrita a um contexto em específico, mas sim em uma lógica subjacente a toda a práxis no serviço. Assim, as reuniões familiares são oferecidas como mais uma modalidade de atendimento que, associada às demais, busca oferecer cuidado ao usuário e às famílias em seus aspectos biopsicossociais.

\section{Cuidado com o Familiar em Semi-Internação}

Os familiares entrevistados entendiam sua participação no tratamento como uma forma de estar presente em uma situação difícil para alguém querido. Entende-se a presença nas atividades promovidas pelo HD como uma forma de não abandonar e, pelo contrário, estar mais próximo e apoiando seu parente. Na prática, esse cuidado se traduz em um sentimento de segurança para o paciente:

Paulo: Eu tenho a impressão que ele se sentia mais seguro sabendo que a gente estava participando aqui. Acho que é uma sensação do... "Eles [os pais] tão aprendendo a fazer direito." (...) Como é que eu diria? "Aprendendo a me ajudar de uma forma mais... mais eficiente. De uma forma melhor." Pra quando ele precisar. (Entrevista 7, Paulo, pai)

Entretanto, esse cuidado é também descrito como uma responsabilidade que, às vezes, está para além do controle do familiar que o assume como sua função. Chama a atenção que geralmente uma única pessoa da família fica responsável pelo cuidado mais próximo do paciente: "Eu acho que isso, assim, na realidade, estar acompanhando ela aqui não foi uma surpresa, porque eu já... Eu já saberia que eu ia ter 
essa responsabilidade, né? De tá junto... Que a pessoa estando sozinha também é complicado, né?" (Entrevista 4, Luísa, filha)

Entender a participação em termos de oferecimento de suporte a alguém querido explicita uma contradição comum em contextos em que familiares ou pessoas próximas se tornam cuidadoras. Por um lado, esse cuidado é visto como um apoio e suporte necessário e oferecido com boa vontade e boa intenção. Por outro, ele também é visto como uma responsabilidade que pode causar sobrecarga devido à demanda que coloca ao cotidiano dessas pessoas. Conforme aponta Cavalheri (2010), esses familiares retratam pessoas "sobrecarregadas com as atribuições a elas impostas, pelo novo modelo de assistência, usurpadas do próprio eu, que passam a viver sentimentos complexos e controversos, e se sentem carentes quanto a informações, orientações e apoio do serviço" (p. 51).

Isso serve para lembrar que a participação da família no tratamento está também associada às várias outras tarefas presentes no cotidiano dessas pessoas, tais como seus empregos e suas ocupações, cuidados com sua própria saúde ou com outros relacionamentos para além daquele com o familiar. Entendemos, assim, ser importante que a oferta de assistência à família se caracterize como uma opção de apoio e suporte, e não como mais uma obrigação que a sobrecarrega. Buscamos, com essa reflexão, nos afastar de uma lógica de disputa pela responsabilização (Pinho et al., 2010): oferecer espaços de atenção à família não significa que ela deve ocupá-los exatamente conforme nossas expectativas.

\section{Cuidado Mútuo entre as Famílias}

Os entrevistados descreveram também seu contato com outras famílias como sendo mutuamente benéfico. Por um lado, a participação junto a outros familiares cria um sentimento de que não se está passando por aquela situação sozinho, afinal, outras famílias enfrentam situações semelhantes ou até mesmo mais difíceis.

Anna: Porque eu acho que é fundamental. Tem que vir. A gente tem que lembrar que tem gente solidária, que tem gente sofrendo tanto quanto ou mais do que a gente, mas que tá ali. É muito gostoso essa troca. É... fortalece muito a gente. (Entrevista 1, Anna, mãe)

Por outro lado, a própria participação é descrita como de potencial ajuda para outros familiares.

Mário: E aquilo, você via os problema dos outros, você via o problema muito perto da gente. Então isso foi abrindo a cabeça da gente. E ai eu acho que me ajudou muito depois daqui também, e quando pessoal se reunia aí... E sempre que chegava gente nova, se não era casal-geralmente era um casal - era mãe e tio às vezes, então eles sempre passavam a bola pra gente. (Entrevista 5, Mário, pai)

Por fim, esse tipo de contato cria uma aproximação entre diferentes famílias e, algumas vezes, promove uma ampliação da rede social e de apoio dessas pessoas.

Paulo: Mas, enfim, nós afinizamos muito com a [Nome de uma familiar que conheceu no serviço]. (...) Ai a Anna [esposa] ia fazer um peixe, falou: "Ah, eu tô pensando em... Tem bastante peixe aqui. Eu tô pensando em chamar alguém, não é? Eu tô pensando em chamar a [Nome da familiar]". Ligamos pra

lá, gostaram da ideia, passamos lá, buscamos, passamos um domingo muito bom. (Entrevista 7, Paulo, pai)

Nas narrativas com essa temática, os familiares apontam novamente para como os efeitos positivos da participação da família no tratamento se tornam possíveis no cotidiano do serviço. Nesse sentido, Rosa (2005) aponta para o potencial do contato entre os familiares ao mostrar a possibilidade de diferentes formas de conviver com o paciente: "Se, por um lado, os familiares cuidadores podem ser homogeneizados em sua condição de vida e na forma como enfrentam os desafios cotidianos, por outro lado há muita riqueza nos encontros" (p. 212).

Além disso, em alguns casos, os relacionamentos iniciados entre familiares no HD são ampliados também para contextos cotidianos dos participantes fora do serviço de saúde mental. Isso pode ser discutido como a ampliação da rede social dessas famílias. Sluzki (1997) conceitua redes sociais como o conjunto das relações que uma pessoa entende como significativas para si mesma e com quem interage com alguma regularidade. Para o autor, existe uma influência mútua entre rede social e saúde, uma vez que a inserção de uma pessoa em uma boa rede social favorece a possiblidade de acesso a ajuda e recursos diversos - apoio emocional ou procura por serviços de saúde.

Pinheiro e Guanaes (2011) apontam um crescente entendimento sobre a potencialidade do trabalho com redes sociais para a ampliação e promoção de saúde de uma forma que valorize a construção de cuidado como inseridas em redes de relacionamentos. No caso dos participantes da presente pesquisa, a transposição de relacionamentos iniciados dentro do serviço para outros contextos pode ser encarada como um fortalecimento de sua rede social e, portanto, uma forma de colaborar para a manutenção da saúde dessas pessoas.

\section{Considerações Finais}

Descrevemos como os sentidos construídos por familiares sobre sua participação no tratamento são diversos, e se referem a algumas formas de participação relacionadas às necessidades plurais dessas famílias. Para esses entrevistados, estar no HD significou sentirem-se cuidados, aprenderem sobre a doença mental, trabalharem relações na família, oferecerem suporte a um parente em uma situação de dificuldade, além de conhecerem outras famílias vivendo situações parecidas, com as quais puderam compartilhar experiências e cuidado.

Como essas diferentes possibilidades de participação se concretizam no cotidiano do serviço? A análise apresentada permite concluir que a construção de um espaço de cuidado para as famílias se dá não apenas mediante o convite para estarem na instituição, mas por meio do efetivo e cotidiano investimento na qualidade das relações entre os atores envolvidos (pacientes, familiares e profissionais). Esse processo acontece a todo momento no dia a dia das práticas de saúde, seja em atividades formalmente estruturadas, seja nos encontros fortuitos em outros espaços no serviço. Que implicações essa conclusão traz para a construção de programas que visem ao cuidado à família? 
Este estudo apontou para o potencial de nos posicionarmos pela parceria com a família e o reconhecimento da importância de seu cuidado no contexto da saúde mental: uma aliança que pode tanto ajudar no cuidado ao paciente, quanto beneficiar seus próprios familiares. Nesse sentido, concordamos com Pinho et al. (2010) em que o protagonismo "é construído na convivência recíproca do cotidiano, quando serviço e família se entendem como parceiros, compartilham as dificuldades e propõem alternativas" (p. 111).

Entendemos que o mérito da criação de ferramentas para o trabalho com as famílias está em preparar e chamar a atenção dos profissionais para a importância dos relacionamentos nos diferentes contextos dos quais participarão junto aos familiares. Trata-se de criar no serviço um cenário rico em recursos que não estão situados em indivíduos específicos, mas na construção de um tipo particular de circunstância que possibilite a emergência de relacionamentos participativos. A cada vez que articulamos esses recursos em diálogo, eles funcionam como lembretes para outras interações que se seguem (Katz \& Alegría, 2009).

A partir deste enquadre, a análise aqui apresentada torna-se importante por duas razões. Primeiro, por ter sido conduzida em um contexto privilegiado de recursos para o trabalho com as famílias que, apesar dos desafios que encontra, está definitivamente acima do padrão mais típico dessas instituições. Assim, este é um serviço que tem um programa estruturado para atendimento de família, conta com uma equipe multidisciplinar, atende baixo número de usuários, e tem profissionais que recebem capacitação frequente. Essas são características incomuns na realidade dos serviços de saúde mental do país.

Segundo, por ter ocorrido em conversas com familiares que produziram "narrativas progressivas", nas quais as pessoas constroem ligações entre suas experiências, de maneira que o movimento da história tem como característica principal o desenvolvimento e a melhora em determinados aspectos, como uma progressão ao longo do tempo (Gergen, 1997). Assim, é possível entender que essas histórias destacam aspectos vividos durante a participação desses familiares no tratamento para os quais os profissionais podem prestar atenção em suas futuras interações nos serviços de saúde mental.

Valorizar a política da produção de cuidado nas interações cotidianas não significa propor nem uma retomada a uma perspectiva clínica tradicional, nem uma separação de contextos micro e macrossociais. Historicamente, parte das preocupações da Psicologia como disciplina tem sido o contato e o cuidado com o humano, desenvolvendo teorias e práticas com essa finalidade. Sendo assim, esses recursos podem ser usados de forma reflexiva, aliados às preocupações mais recentes do campo: a saúde coletiva, a saúde pública, a política pública e, sobretudo, o compromisso com a transformação social (Benevides, 2005). Nesse caso, concordamos com Ferreira Neto (2008) em que a noção de clínica ampliada pode ser uma forma de manejar a infértil tensão entre clínica e política. Entender a subjetividade como entrelaçada à cidadania transforma as formas de serviço oferecidas, além dos objetos e dos objetivos aos quais o tratamento se direciona.
Em conclusão, tomamos a preocupação de Benevides (2005) a respeito das aproximações da Psicologia ao SUS como um convite para pensar também a participação da família no tratamento: "O que queremos ressaltar é que os eixos da universalidade, equidade e integralidade, constitutivos do SUS, só se efetivam quando conseguimos inventar modos de fazer acontecer tais eixos. Interessa-nos perguntar o como fazer (...)” (p. 24). Então, continuemos sempre a nos perguntar: como fazer? Como inventar, no cotidiano dos serviços, formas de prática com essas famílias que sejam responsivas às suas necessidades, benéficas para o paciente em regime de semi-internação e que promovam a cidadania e transformação social?

Esperamos que este artigo, ao investigar as descrições de alguns familiares sobre sua participação no cotidiano dos serviços, tenha trazido algum entendimento sobre o assunto. Questão complexa e importante, que parece oferecer caminhos promissores se conseguirmos trabalhar nas interfaces entre clínica e política, enxergando pessoas que sofrem desamparadas à nossa frente, mas cheias de possibilidades e potencialidades. Cidadãos merecedores de, e sobretudo detentores do direito a assistência e cuidado. Caminhos promissores em um campo concreto e possível, no qual entendemos que o cotidiano dos serviços representa um local privilegiado para a construção do cuidado às famílias.

\section{Referências}

Aman, M. G. (2005). Treatment planning for patients with autism spectrum disorders. Journal of Clinical Psychiatry, 66(10), $38-45$.

Benevides, R. (2005). A Psicologia e o Sistema Único de Saúde: Quais interfaces? Psicologia \& Sociedade, 17(2), 21-25. doi: 10.1590/S0102-71822005000200004

Brasil, Ministério da Saúde. (1996). Resolução no 196/96 sobre pesquisa envolvendo seres humanos. Brasília: Conselho Nacional de Saúde.

Brasil, Ministério da Saúde. (2005). Reforma psiquiátrica e política de saúde mental no Brasil. Brasília: Secretaria de Atenção à Saúde.

Brasil, Ministério da Saúde. (2010). Cadernos HumanizaSUS. Brasília: Secretaria de Atenção à Saúde.

Campos, R. O. (2001). Clínica: a palavra negada - Sobre as práticas clínicas nos serviços substitutivos de saúde mental. Saúde em Debate, 25(58), 98-111.

Cavalheri, S. C. (2010). Transformações do módulo assistencial em saúde mental e seu impacto na família. Revista Brasileira de Enfermagem, 63(1), 51-57. doi: 10.1590/S003471672010000100009

Costa-Rosa, A. (2000). O modo psicossocial: Um paradigma das práticas substitutivas ao modo asilar. In P. Amarante (Ed.), Ensaios: Subjetividade, saúde mental, sociedade (pp. 141-168). Rio de Janeiro: Fiocruz.

De Leon, G. (2003). A comunidade terapêtica: Teoria, modelo e método (C. A. Bárbaro, Trad.). São Paulo: Edições Loyola.

Felício, J. L., \& Almeida, D. V. (2008). Abordagem terapêutica às famílias na reabilitação de pacientes internados em hospitais psiquiátricos: Relato de experiência. Mundo Saúde (1995), 32(2), 248-253. 
Ferreira Neto, J. L. (2008). Práticas transversalizadas da clínica em saúde mental. Psicologia: Reflexão \& Crítica, 21(1), 110-118. doi: 10.1590/S0102-79722008000100014

Gergen, K. J. (1997). Realities and relationships. Cambridge: Harvard University Press.

Gonçalves, A. M., \& Sena, R. R. (2001). Reforma psiquiátrica no Brasil: Contextualização e reflexos sobre o cuidado com o doente mental na família. Revista Latinoamericana de Enfermagem, 9(2), 48-55. doi: 10.1590/S0104-11692001000200007

Goodman, D., \& Happell, B. (2006). The efficacy of family intervention in adolescent mental health. International Journal of Psychiatric Nursing Research, 12(1), 1364-1377.

Gross, V., \& Goldin, J. (2008). Dynamics and dilemmas in working with families in Inpatient CAMH services. Clinical Child Psychology and Psychiatry, 13(3), 449-461. doi: 10.1177/1359104507088350

Guanaes, C. (2000). Grupo de apoio com pacientes psiquiátricos ambulatoriais: exploração de alguns limites e possibilidades (Dissertação de Mestrado). Faculdade de Filosofia, Ciência e Letras de Ribeirão Preto, Universidade de São Paulo, Ribeirão Preto.

Guanaes-Lorenzi, C., Palacio, M. B., Aoki, F. C. O. S., \& Tofoli, S. M. C. (2015). Superando o discurso do déficit no trabalho com famílias em contextos de saúde mental. In R. M. S. Macedo (Org.), Expandindo horizontes em terapia familiar (pp. 01-38). Curitiba: Editora CRV.

Guanaes-Lorenzi, C., Santos, M. V., Brunini, F. S., Ishara, S., Tofoli, S. M. C., Real, E. M. A. (2012). Construção de um Programa de Assistência Familiar em um Hospital-Dia Psiquiátrico: Desafios e Potencialidades. Nova Perspectiva Sistêmica, 43, 54-72.

Katz, A. M., \& Alegría, M. (2009). The clinical encounter as a local moral world: Shifts of assumptions and transformation in relational context. Social Science \& Medicine, 68, 1238-1246. doi: 10.1016/j.socscimed.2009.01.009

Kondo, A., \& Wada, K. (2009). The effects of a mutual-help group activity for drug users and family members in Japan. Substance Use \& Misuse, 44(4), 472-489. doi: 10.1080/10826080701801501

Lucksted, A., Stewart, B., \& Forbes, C. B. (2008). Benefits and changes for family to family graduates. American Journal of Community Psychology, 42(1-2), 154-166. doi: 10.1007/ s10464-008-9195-7

Martins, P. P. S. (2013). A participação da família no tratamento em Saúde Mental como prática no cotidiano do serviço (Dissertação de Mestrado). Faculdade de Filosofia, Ciências e Letras de Ribeirão Preto, Universidade de São Paulo, Ribeirão Preto.
McNamee, S., \& Gergen, K. J. (1992). Therapy as social construction. Thousand Oaks: Sage.

McNamee, S., \& Hosking, D. M. (2011). Research and social change: A relational constructionist approach. New York/ Oxford: Routledge.

Pinheiro, R. L., \& Guanaes, C. (2011). O conceito de rede social em saúde: Pensando possibilidades para a prática na estratégia saúde da família. Nova Perspectiva Sistêmica, 40, 9-25.

Pinho, L. B., Hernández, A. M. B., \& Kantorski, L. P. (2010). Reforma psiquiátrica, trabalhadores de saúde mental e a parceria da família: O discurso do distanciamento. Interface (Botucatu), 14(32), 103-113. doi: 10.1590/S141432832010000100009

Rosa, L. C. S. (2005). A inclusão da família nos projetos terapêuticos dos serviços de saúde mental. Psicologia em Revista, 11(18), 205-218.

Rose, S. L., \& Shelton, W. (2006). The role of social work in the ICU: Reducing family distress and facilitating end-of-life decision-making. Journal of Social Work in End-of-Life \& Palliative Care, 2(2), 3-23.

Serapioni, M. (2005). O papel da família e das redes primárias na reestruturação das políticas sociais. Ciência \& Saúde Coletiva, 10(0), 243-253. doi: 10.1590/S1413-81232005000500025

Silva, K. V. L. G., \& Monteiro, A. R. M. (2011). A família em saúde mental: Subsídios para o cuidado clínico em enfermagem. Revista da Escola de Enfermagem da USP, 45(5), 1237-1242. doi: 10.1590/S0080-62342011000500029

Sluzki, C. E. (1997). A rede social na prática sistêmica: Alternativas terapêuticas. São Paulo: Casa do Psicólogo.

Spink, M. J. P. (Ed.) (2004). Práticas discursivas e produção de sentidos no cotidiano: Aproximações teórico e metodológicas. São Paulo: Cortez.

Spink, M. J. P. (2010). Ser fumante em um mundo antitabaco: Reflexões sobre riscos e exclusão social. Saúde \& Sociedade, 19(3), 481-496. doi: 10.1590/S0104-12902010000300002

Toumbourou, J. W., \& Bamberg, J. H. (2008). Family recovery from youth substance use related problems: A pilot study of the BEST Plus program. Substance Use \& Misuse, 4(12-13), 1829-1843. doi: 10.1080/10826080802297385

Vasconcelos, E. M. (1990). Avaliação dos avanços recentes em legislação psiquiátrica no plano internacional: uma contribuição ao debate sobre a reforma da lei psiquiátrica no Brasil. Jornal Brasileiro de Psiquiatria, 39, 235-288.

Recebido em 23.05.2013

Primeira decisão editorial em 06.06.2016

Versão final em 16.06.2016

Aceito em 24.10.2016 